\title{
A Letter from the Editor
}

DALE E. MILLER

Old Dominion University

I began to transition into the role of editor-in-chief of Utilitas in the spring of 2016 and fully assumed the position late in the summer. Since volume 29 will be the first for which I am entirely responsible, this seems like an appropriate juncture for me to say a few words about my plans for the journal.

First, though, I would like to offer my thanks to the earlier editors - Fred Rosen, Roger Crisp, Paul Kelly and Brad Hooker - for the hard work that was involved in making the journal a leading venue for work in ethics, political theory, economics, legal thought and intellectual history. I feel extremely fortunate to have inherited a journal that is so well-regarded by both its contributors and its readers, and I will endeavour to maintain its reputation. I am especially grateful to Brad, my immediate predecessor, for his help and encouragement as I eased into my new responsibilities. He will now join the other former editors as an associate editor.

Since assuming the position of editor I have made two changes to the journal's editorial procedures. First, I have invited Rachel Carter to join us as managing editor. Rachel inspects new submissions when they first arrive to ensure that they are properly formatted. She then sends me anonymous copies of articles so that I can decide which to send out for review without knowing the authors' identities. (We do not yet have the resources necessary for true triple-blind review, in which the editor remains unaware of the author's identity through the entire review process, but I hope that this will be possible in the future.) When articles are accepted Rachel also plays a role in preparing them for production. I am very grateful for the efficient assistance that she provides. Second, I have imposed length limits on submissions. We now require that research articles be no longer than 10,000 words, and prefer that they be under 8,000. Discussion notes are limited to 4,500 words.

In addition to implementing these new procedures, I have also reaffirmed Utilitas's distinctive mission as a journal of utilitarian or, more generally, consequentialist thought. I particularly welcome submissions that engage in some way with the consequentialist tradition, broadly construed. This includes work on figures in the history of this tradition as well as work on topics of contemporary 
interest, and of course it also includes contributions that are critical of utilitarian and consequentialist arguments and positions. While this does not mean that the journal will no longer consider any work that does not engage with this tradition, the bar will be higher for such work.

David Weinstein will continue to serve as the journal's reviews editor, and I would like to thank him for his long tenure in this often thankless task. Philip Schofield will likewise continue to serve as an associate editor, and I would also like to express my appreciation for his many years of support for the journal both in this capacity and as secretary of the International Society for Utilitarian Studies. Final words of thanks go to the unfailingly helpful journals staff at Cambridge University Press, the members of the journal's editorial board and the many people who have already responded positively to my requests that they serve as reviewers for articles. 